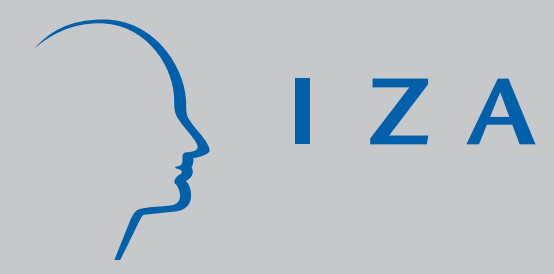

IZA DP No. 4094

The Effect of Neighbourhood Housing Tenure Mix on Labour Market Outcomes: A Longitudinal Perspective

Maarten van Ham

David Manley

March 2009 


\title{
The Effect of Neighbourhood Housing Tenure Mix on Labour Market Outcomes: A Longitudinal Perspective
}

\author{
Maarten van Ham \\ University of St Andrews \\ and IZA \\ David Manley \\ University of St Andrews
}

Discussion Paper No. 4094
March 2009

\author{
IZA \\ P.O. Box 7240 \\ 53072 Bonn \\ Germany \\ Phone: +49-228-3894-0 \\ Fax: +49-228-3894-180 \\ E-mail: iza@iza.org
}

Any opinions expressed here are those of the author(s) and not those of IZA. Research published in this series may include views on policy, but the institute itself takes no institutional policy positions.

The Institute for the Study of Labor (IZA) in Bonn is a local and virtual international research center and a place of communication between science, politics and business. IZA is an independent nonprofit organization supported by Deutsche Post Foundation. The center is associated with the University of Bonn and offers a stimulating research environment through its international network, workshops and conferences, data service, project support, research visits and doctoral program. IZA engages in (i) original and internationally competitive research in all fields of labor economics, (ii) development of policy concepts, and (iii) dissemination of research results and concepts to the interested public.

IZA Discussion Papers often represent preliminary work and are circulated to encourage discussion. Citation of such a paper should account for its provisional character. A revised version may be available directly from the author. 
IZA Discussion Paper No. 4094

March 2009

\section{ABSTRACT}

\section{The Effect of Neighbourhood Housing Tenure Mix on Labour Market Outcomes: A Longitudinal Perspective}

This paper investigates the effect of different levels of neighbourhood housing tenure mix on transitions from unemployment to employment and the probability of staying in employment for those with a job. We used individual level data from the Scottish Longitudinal Study (SLS), a $5.3 \%$ sample of the Scottish population, covering a 10 year period. We found a strong negative correlation between living in deprived neighbourhoods and labour market outcomes (getting or keeping a job). We found a small, but significant, positive correlation between living in mixed tenure (40-80\% social housing) streets and transitions from unemployment to employment. In the conclusion we discuss the extent to which we think these results can be interpreted as 'neighbourhood effects' or selection effects.

JEL Classification: $\quad$ I30, J60, R23

Keywords: tenure mix, deprivation, neighbourhood effects, labour market transitions, longitudinal data, Scotland

Corresponding author:

Maarten van Ham

Centre of Housing Research

School of Geography \& Geosciences

University of St Andrews

Irvine Building, North Street, KY16 9AL

St Andrews, Fife

United Kingdom

E-mail: maarten.vanham@st-andrews.ac.uk 


\section{The Effect of Neighbourhood Housing Tenure Mix on Labour Market Outcomes: A Longitudinal Perspective}

\section{Introduction}

Unemployment is a major concern for governments and is considered one of the principal social evils facing Europe in modern times (EU, 1998; OECD, 1997). Most policies to keep unemployment levels low and to get the unemployed back to work involve training and financial incentives (Schömann \& O’Connell, 2002) but policies are also designed to help cities and regions attract employment opportunities. In recent years, neighbourhood level policies to attack unemployment have become increasingly popular. These policies are rooted in a firm belief in so-called neighbourhood effects: the assumed negative effect of deprived neighbourhoods on residents' social opportunities (see for a review Sampson et al., 2002; Durlauf, 2004).

The neighbourhood effects literature argues that large "concentrations of deprivation give rise to problems greater than the sum of the parts" and as such are thought to introduce negative effects to those living in concentration areas (McCulloch 2001, p667). These negative effects include "disconnection from jobfinding networks, high levels of crime, the absence of employed or educated role models, and for children and young people [the absence of] peer groups lacking educational aspirations" (Tunstall \& Fenton, 2006 p12). In some neighbourhoods a 'culture of poverty' is present, leading to dysfunctional values (Wilson, 1987). It has also been argued that social isolation in poor neighbourhoods makes it harder to find and keep employment (Wilson, 1987).

Neighbourhood level policies generally aim at creating a more favourable socio-economic mix of residents in neighbourhoods, providing unemployed residents with networks and role models and creating a culture of employment. Mixed housing tenure policies are often used as a vehicle to create more socially mixed neighbourhoods. The idea is that mixing homeowners with social renters will create a more diversified socio-economic mix in neighbourhoods (Musterd \& Anderson, 2005). Mixed housing strategies are stated explicitly by many governments such as those in the Netherlands, the United Kingdom, Germany, France, Finland, and Sweden (Atkinson \& Kintrea, 2002; Kearns, 2002; Musterd, 2002).

The evidence that mixed tenure policies have the desired effect is inconclusive (Musterd \& Andersson, 2005) and is generally not very convincing. To our knowledge, the majority of existing work is either ecological in nature (Priemus, 1998; Graham et al., 2009; Smith, 1999; Tunstall, 2003) or cross sectional (Lee et al., 1994; Ostendorf et al., 2001; Jupp, 1999; McCulloch, 2001; Martin \& Watkinson, 2003). The ecological work looks at the correlation between the percentage of social housing in a neighbourhood and, for example, the level of unemployment. Although the ecological approach gives us some indication of the relationship between the two, individual level analyses are needed to further our understanding of how tenure mix affects individual labour market outcomes. The main problem with cross sectional work is the identification of causal relationships. Those living in predominantly socially rented neighbourhoods might be more likely to be unemployed, but this does not mean that the neighbourhood has anything to do with their unemployment status. It is more likely that those who are unemployed selected themselves into these neighbourhoods. To tackle the problem of causality it is necessary to use longitudinal 
data (Bolster et al., 2007; Galster et al., 2008). An additional problem with existing work on neighbourhood effects is the identification of the appropriate spatial scale of analysis: how to define the relevant neighbourhood level? (Lee et al., 1994; Galster, 2001; Bolster et al., 2007).

The main aim of this paper is to further our understanding of the effect of neighbourhood tenure mix on individual employment outcomes. We will study labour market transitions from unemployment to employment and the probability of staying in employment for those with a job. This paper contributes to the existing literature in three ways. First, we use individual level data; second, we use longitudinal data; and third, we investigate the effect of geographical scale by using two different definitions of neighbourhoods. We use unique data from the Scottish Longitudinal Study (SLS) which is a 5.3\% sample of the Scottish population linked through time by matching Census forms from 1991 and 2001. Using this data we are able to link 1991 neighbourhood characteristics (using two definitions of neighbourhoods) to 2001 labour market outcomes. We will attempt to answer the following two questions:

1. To what extent does 1991 neighbourhood tenure mix influence the probability that those who are unemployed in 1991 have a job in 2001?

2. To what extent does 1991 neighbourhood tenure mix influence the probability that those who are employed in 1991 still have a job in 2001?

\section{Background}

There is an extensive literature investigating the effect of neighbourhood characteristics on an individual's life chances (see for excellent overviews Dietz, 2002; Durlauf, 2004; Bolster et al., 2007). Wilson (1987) is generally seen as the starting point of the resurgence of interest in neighbourhoods (Durlauf, 2004). According to Wilson (1991, p.650) "[t]he central problem of the underclass is joblessness reinforced by increasing social isolation in impoverished neighbourhoods, as reflected, for example, in the residents' declining access to job information network systems". The structural 'concentration effects' argument by Wilson is closely related to the spatial mismatch hypothesis coined by Kain (1968). According to the original spatial mismatch hypothesis, poor African-American residents of inner city neighbourhoods in the US were unemployed because employment opportunities had moved away from the inner city to suburbs and the poor could not afford to commute to these locations (see also Preston \& McLafferty, 1999). Distance does not only influence the ability to get to a job, but can also influence the possibilities of individuals finding out about work. "There is evidence that for non-skilled and semiskilled jobs the employers' hiring practices and the search behaviour of job applicants are affected by extremely local circumstances" (Preston \& MacLafferty, 1999 p.397, see also Van Ham, 2002; Gobillion et al., 2007).

Additional explanations of neighbourhood effects are based on role model effects or peer group influences (Manski, 2000; Blume \& Durlauf, 2001; Brock \& Durlauf, 2003). The idea is that a lack of role models - people with education and a job - in some neighbourhoods causes low expectations of what residents think they can achieve in their current situation (Bolster et al., 2007). In extreme cases this can lead to a 'culture of poverty' effect (Wilson, 1987) where unemployment is not a consequence of structural problems but of a cultural commitment to dysfunctional and irrational values resulting in the wish of the 'underclass' to follow alternative values counter to the norms of society. The rejection of these norms may lead to an increased 
participation in anti-social activities, and opting out of education and employment. The culture of poverty argument can turn into a structural neighbourhood effect when employers refuse to hire residents from certain neighbourhoods based on the reputation of the neighbourhood as a whole (see Permentier et al., 2007).

Most existing studies on neighbourhood effects focus on the negative effects of living in deprived neighbourhoods, often measured using indices of deprivation, or the percentage of residents on low incomes or unemployment benefits. The empirical evidence from studies investigating whether neighbourhood effects exist is mixed (Bolster et al., 2007). Durlauf (2004) reports that quasi-experimental studies, such as Gautreaux and the Moving to Opportunity program (Rosenbaum, 1995; Katz et al., 2001; Ludwig et al., 2001; Goering et al., 2002; Kling et al., 2004) find little impact on adults' outcomes while the bulk of non-experimental observational studies (see for examples using the British Household Panel Survey McColluch, 2001; Buck, 2001) do find effects. Durlauf (2004) identifies a range of conceptual and statistical problems that might explain why many observational studies find a negative effect of deprived neighbourhoods on individual outcomes. Identification of causal effects is the main problem. This is most acute in Manski's (1993) reflection problem and related issues of (self) selection, but also omitted variable bias plays a role (Moffitt, 2001; Brock \& Durlauf 2001, 2003; Durlauf, 2004). Using longitudinal data instead of cross-sectional data can solve part of the problems; see for example work by Musterd (2002), Musterd and Anderson (2005), Bolster and colleagues (2007) and Galster and colleagues (2008). A major difficulty in neighbourhood research is identifying the relevant spatial scale of the neighbourhood and often the choice is driven by the availability of data and the detail of geo-references available. Both Buck (2001) and Bolster and colleagues (2007) found that local neighbourhoods provide more explanation than broader ones, showing how scale is crucial to the understanding of the effects identified. From this we may conclude that some studies might simply use the 'wrong' neighbourhoods.

Given the lack of conclusive evidence that neighbourhood effects exist, it is somewhat surprising that many policy makers, especially in the European context, have so enthusiastically embraced policies to create mixed neighbourhoods. See, for example policy documents for Scotland: Scottish Homes, 2001; Communities Scotland, 2004; Scottish Government, 2006; Scottish Government, 2007. The general idea is that dispersing concentrations of poverty helps remove (part of) the problem (Hochschild, 1991). A popular strategy is to create more socially mixed neighbourhoods through creating mixed housing tenure neighbourhoods. It is assumed that mixing those in social renting with homeowners facilitates labour market access of the poor through the introduction of job networks and positive role models, breaking down cultures of poverty. Whether or not living in mixed tenure neighbourhoods leads to better outcomes for individuals compared to living in concentrations of social housing is an important question. Vast amounts of money are invested in creating mixed tenure neighbourhoods and this money might be better spent on investing in individuals and education.

There are several existing studies investigating whether mixed tenure neighbourhoods have more positive effects on individual outcomes than predominantly socially rented neighbourhoods (e.g. Schwartz \& Tajbakhsh, 1997; Power, 1997; Jupp, 1999; Pawson et al., 2000; Aktinson \& Kintrea, 2000; Kleinman, 2000; Ostendorf et al., 2001, Smith, 2001; Wood, 2003; Arthurson, 2005). As discussed in the introduction, most of these studies are either ecological or crosssectional in nature, limiting their value in investigating causality. The evidence from 
these mostly small scale studies is varied, providing little basis for generalization. Atkinson and Kintrea (1998), for example, interviewed residents of a mixed tenure development in Edinburgh, Scotland and found that there was little interaction between renters and owners and that employment outcomes were not benefited by living in a mixed neighbourhood. Jupp (1999) used a survey of residents of 10 estates across Britain with various proportions of social housing to investigate social interaction between residents. Jupp showed that interactions were highly spatially concentrated and that little interaction occurred between tenure groups. It was also found that residents of mixed tenure estates did not perceive tenure mix as beneficial (Jupp, 1999).

A good example of an ecological study is a paper by Graham and colleagues (2009) using 1991 and 2001 Census data to investigate the effects of tenure mix across the whole of Great Britain. They found that Census Wards (around 5000 people) with less than $30 \%$ social renting had lower levels of unemployment, less people experiencing poor health and less premature deaths and mortality than Wards with more than $30 \%$ social renting. The same analyses on a lower geographical scale (Output Areas, with on average 140 people in the UK) showed significant disadvantage for areas with more than $60 \%$ social renting. Graham and colleagues (2009) identified the need to use individual level data, exploring different geographical scales, to come to a better understanding of the effects of neighbourhood tenure mix.

To our knowledge, the only work explicitly investigating the effect of tenure mix on employment using large scale longitudinal data is by Musterd and Anderson (2005) for Sweden. Musterd and Anderson used a series of cross tabulations to investigate to what extend tenure mix and social mix are associated on the neighbourhood level and how changes in employment status of individuals between 1991 and 1999 were related to the (social) homogeneity of neighbourhoods. An entropy measure was used to describe the variety of tenures in neighbourhoods and social mix was measured using data on the distribution of work related income. They demonstrated that in Sweden, tenure mix does not necessarily result in income mix. Those most likely to stay in employment over time lived in high income neighbourhoods with an either a very homogeneous or very heterogeneous tenure structure. Those living in low income neighbourhoods with an either homogeneous or very heterogeneous tenure structure were much less likely to stay in employment with those in the heterogeneous areas having the worst outcomes. Musterd and Anderson (2005) concluded that compared to living in mono tenure neighbourhoods, living in mixed tenure neighbourhoods does not automatically lead to better employment outcomes. Surprisingly they did not distinguish between mono ownership and mono social renting neighbourhoods while one would expect very different outcomes.

In this paper we will investigate the effect of different levels of tenure mix on individual labour market outcomes for Scotland. Over the last few decades, social housing policies in Scotland have resulted in the creation of large mono-tenure estates, which still exist despite erosion through the Right-to-Buy (Jones \& Murie, 2006) and redevelopment. These large estates of social renting tend to represent concentrations of poverty, where especially long term unemployment is a problem. In this paper we will investigate whether these high concentrations of social renting have a negative effect on transitions from unemployment to employment and the probability to stay in employment for those with a job. We will not only investigate the effect of tenure mix on labour market transitions, but also whether tenure mix offers an explanation over and above measures of deprivation. Our work is by no 
means free of all the problems commonly found in the neighbourhood effects literature as identified by Durlauf (2004). However, by using individual level longitudinal data, covering a 10 year period and by investigating the effect of different levels of mixing and explicitly testing the effect of the geographical scale of neighbourhoods we believe that our study offers a worthwhile contribution to the mixed tenure and neighbourhood effects literature.

\section{Data and Methods}

The individual-level data were assembled from the Scottish Longitudinal Study (SLS) a 5.3\% sample of the Scottish population linked through time by matching Census forms from 1991 and 2001 (Boyle et al., forthcoming). Approximately 274,000 SLS members were identified from the 1991 census and information for these individuals was linked from the 2001 census. This design allows researchers to follow the same individuals over a 10 year period, investigating the effect of 1991 characteristics on 2001 outcomes. A unique feature of the data, which makes it highly suitable for our purposes, is that the data are geocoded: researchers have the possibility to link area characteristics on a low geographical scale to individual SLS members.

The research population for this paper consisted of all individuals who were aged between 15 and 50 years old in 1991 (so between 25 and 60 years old in 2001), and excluded people who were in education, giving care, or retired. We identified 3,639 individuals who were unemployed in 1991, of which 2,609 had a job in 2001. We also identified 60,048 individuals who were employed in 1991, of which 58,563 still had a job in 2001. All individuals with a part time or a full time job were classified as employed. Individuals who stated that they had secured a job, but had not yet started were also treated as employed. It is important to note that the SLS data does not contain any employment related information for the period in-between 1991 and 2001. This means that while an SLS member might have been unemployed in both 1991 and 2001, this person might have had jobs between these two years. Although we recognize the limitations this creates for our analyses, we argue that the unique characteristics of the SLS (longitudinal, large sample size and detailed geocoding) more than outweigh the disadvantages.

The dependent variable in our first models indicates whether those who were unemployed in 1991 are unemployed (0) or employed (1) in 2001. The dependent variable in our second models indicates whether those who were employed in 1991 are unemployed (0) or employed (1) in 2001. Since both dependent variables are binary, we used logistic regression models. Because the models included both individual level characteristics and area level characteristics and the data included multiple individuals per area, the standard errors have been adjusted for clustering of individuals on the area level.

We included a wide range of individual and household characteristics in our models. An overview of these variables can be found in Table 1. Age, gender, ethnicity, housing tenure, and a variable indicating whether the SLS member had a working partner were all measured for 1991. For the SLS members without a partner, the average of the respondents with a partner is substituted. Because the model contains a variable indicating whether a partner is present, this substitution of the means leads to unbiased coefficients of the 'partner works' dummy for those with a working partner (compare Cohen and Cohen, 1975, chapter 7). We opted for 1991 housing tenure to avoid reverse causality problems. It would be wrong to associate a 
transition from unemployment to employment between 1991 and 2001 with 2001 tenure because the 2001 tenure might be the result and not the cause of the transition. Level of education was measured in 2001 because of classification problems with the 1991 data. Using 2001 level of education is not likely to cause causality problems. We also included several variables indicating change between 1991 and 2001: change in self reported health; change in household composition, change in the presence of children; and a variable indicating whether or not an SLS member had moved between 1991 and 2001.

The outcomes of our models are possibly affected by omitted variable bias which arises when unobserved variables are correlated with included variables. A possible strategy to deal with omitted variable bias is to use a fixed effects model, which controls for all measured and unmeasured static individual and neighbourhood level characteristics (such as gender, ethnicity, but also whether someone is, for example, a 'risk taker'). The dependent and independent variables in a fixed effects model measure change between two points in time (see Galster et al, 2008 for an example of a difference model). Although a fixed effects model deals with omitted variable bias, it also introduces other problems (Allison, 2005). Using a fixed effects model we would not be able to include static neighbourhood characteristics, only changes in characteristics between 1991 and 2001. As many of the SLS members moved between 1991 and 2001, the 2001 neighbourhood characteristics (and therefore the change between 1991 and 2001) could be a result rather than a cause of labour market transitions. For example, people could have moved to a better neighbourhood after they found a (better) job (see also Bolster et al., 2007). Therefore, we have decided not to use a fixed effects model.

\section{--- Table 1 ---}

The SLS data is geocoded, allowing researchers to link area level characteristics to the residential location of each SLS member. We included three area level characteristics in our models: an urban-rural classification, a measure of housing tenure mix and a measure of deprivation. The area descriptors were all measured for 1991 and are therefore not allowed to vary over time. The main reason for fixing the area characterisation in time is identification of causality (see above).

The urban-rural classification is based on population size and access to concentrations of population (Scottish Executive, 2004) and measured in 6 categories: cities (over 125,000 people); urban areas (10,000 to 125,000 people); small towns (3,000 to 10,000 people or further than 30 minutes from towns with 10,000 people or more); accessible rural (less than 3,000 people and less than 30 minutes from places with over 10,000 people); and remote (settlements with under 3,000 people and over 30 minutes from places with over 10,000 people). The urban-rural classification serves as a proxy for access to job opportunities (see also Van Ham, 2001).

We used the percentage of social renting in an area as a measure of housing tenure mix. In Scotland owner occupation is the majority tenure (52.4\% in 1991), followed by social renting (40.3\%) and private renting (7.3\%). Because it is highly unlikely that the relationship between neighbourhood tenure mix and labour market transitions is linear (see Galster, 2007) we used 5 categories to describe the level of social renting: $0-20 \%$; $20-40 \%$; $40-60 \%$; $60-80 \%$; and $80-100 \%$. We consider the middle three categories as mixed tenure areas, while the extremes at each end of the distribution can be thought of as mono-tenure areas. To measure the level of deprivation in an area we used the Carstairs index (Carstairs \& Morris, 1990) which is 
based on the level of male unemployment in an area, the number of households without a car, the level of overcrowding (over 1 person per room), and the social class of heads of households (categories IV and V). Deprivation was measured in 5 categories (quintiles), each containing $20 \%$ of the overall deprivation distribution.

There is much debate on what is the best way to define 'neighbourhoods' using administrative data (Kearns \& Parkinson, 2001; Galster, 2001; Manley et al., 2006). Several studies have compared outcomes for different geographical scales and found significant differences (See Buck, 2001; Bolster et al., 2007; Graham et al., 2009). We are aware that there is no one-to-one relationship between administrative areas and neighbourhoods as perceived by residents (see Galster, 2001), but it can be argued that smaller areas come closer to what people may perceive as their neighbourhood than larger areas. We estimated separate models using area level characteristics measured on two geographical scales: CATTs and Output Areas. In Scotland there are 42,604 Output Areas (OA's) containing on average 119 individuals. CATTs (Consistent Areas Through Time) are more extensive areas with an average population of 503 (ranging from 50 to 18,510 people). Output Areas and CATTs are hierarchical, and the OAs all nest conterminously within CATTs.

\section{Results}

\section{Transition from unemployment in 1991 to employment in 2001}

Table 2 show the results of two logistic regression models estimating the probability of employment in 2001 for those unemployed in 1991. The difference between Model 1 and Model 2 is that the second model also includes a measure of neighbourhood level deprivation. We first briefly discuss the effects of the control variables before discussing the effects of the main variables of interest: the neighbourhood level characteristics measured at the CATT level. As a general observation it is interesting that, as expected, the coefficients for the neighbourhood level variables are smaller than the coefficients for the individual level characteristics, indicating that individual level characteristics are more important in explaining labour market outcomes.

The results show that unemployed women in 1991 are more likely to be in employment in 2001 than men who were unemployed in 1991. With increasing level of education the probability to be employed in 2001 increases. Social renters and private renters are less likely gain employment than owners. People with a working partner are more likely to be employed than people without a working partner. The above results are in line with what we would expect based on the labour market literature (e.g. Van Ham, 2002).

Next a set of variables indicating change between 1991 and 2001 is included in the models. Compared to those without a self-reported limiting long term illness in either 1991 or 2001, those with a long term limiting illness in only 2001 are less likely to be in employment in 2001. Compared to SLS members who were a couple in both 1991 and 2001, singles in both years and those who became single between 1991 and 2001 are less likely to be employed in 2001. SLS members without children in both years are less likely to be employed in 2001 compared to SLS members with children in both years. Although not significant, the interaction effect between female and the dummy indicating whether an SLS member had moved between 1991 and 2001 is negative as expected. This is in line with the family migration literature which shows that household moves do not generally benefit the labour career of women (Boyle et al., 2001). 
The urban-rural characterisation, a proxy for access to employment, does not have a significant effect on labour market transitions. The only exception is that compared to those living in the most remote parts of Scotland, those living in accessible rural areas are slightly more likely to be in employment in 2001. The next neighbourhood level variable included in the model is the main variable of interest: the percentage of social renting at the CATT level. Based on the literature we expected that unemployed people living in a neighbourhood with a high percentage of social renting in 1991 have a lower probability of employment in 2001 than people living in an area with a low percentage of social housing. The results in Model 1 show that compared to those in mono ownership neighbourhoods (0-20\% social housing), those in mono social renting neighbourhoods (80-100\% social housing) are significantly less likely to be in employment in 2001. However, there is no significant difference between living in mono-ownership neighbourhoods and living in mixed tenure neighbourhoods (20-40\%, 40-60\% and 60-70\% social renting).

In Model 2 we also included a measure of the level of deprivation on the CATT level. Neighbourhood level deprivation (a measure of poverty in the neighbourhood) is the classic neighbourhood characteristic used in the neighbourhood effects literature following the work by Wilson (1987). Based on the literature we would expect that the unemployed living in the most deprived neighbourhoods in 1991 are the least likely to be in employment in 2001. The results in Model 2 confirm that those living in the two most deprived categories of CATT areas are the least likely to be employed in 2001. Interestingly, the effects for the percentage of social renting on employment disappears after controlling for deprivation. This indicates that at the CATT level, neighbourhood deprivation is the underlying mechanism explaining the negative effect of high concentrations of social housing on employment.

\section{--- Table 2 ---}

\section{Staying in employment 1991-2001}

Table 3 shows the results for two logistic regression models estimating the probability of being in employment in 2001 for those employed in 1991. The difference between Model 3 and Model 4 is that the second model also includes a measure of CATT level deprivation. Most of the effects of the control variables in Models 3 and 4 (with a research population of employed SLS members in 1991) are the same as in Models 1 and 2 (with a research population of unemployed SLS members in 1991). Here we will only briefly discuss the differences. In Model 1 and 2 the effect of belonging to an ethnic minority group on the probability to be employed was not significant. In Models 3 and 4 the effect is significant. Of those employed in 1991, those belonging to an ethnic minority group are less likely to be employed in 2001 than others. In Models 3 and 4 the effect of changes in self reported health are more pronounced compared to Models 1 and 2. Those who reported a limiting long term illness in both 1991 and 2001 are the least likely to be in employment in 2001. In Models 3 and 4 the effect of the dummy indicating that the SLS member had moved between 1991 and 2001 is significant. The effect indicates that those who moved are more likely to be in employment in 2001 than those who had not moved. The interaction effect between the mover status dummy and the female dummy indicates that female SLS members who moved are less likely to be employed in 2001 compared to males and female non-movers. This is in line with the family migration literature.

There is no significant effect of the urban-rural indicator (proxy for access to job opportunities) on the probability of being in employment in 2001 for those who 
were in employment in 1991. The variable measuring the percentage of social renting on the CATT level shows that those living in areas with $20-40 \%$ social renting are slightly more likely to be employed in 2001 than those living in an area with less than $20 \%$ social renting, although the effect is hardly significant. Those in areas with $60 \%$ or more social housing are the least likely to be employed in 2001. This is in line with the expected negative effect of concentrations of social housing on employment.

In Model 4 we included a CATT level measure of deprivation. Compared to Model 3, the effects of the control variables stay roughly the same. After including the deprivation measure, the negative effect of living in an area with a high percentage of social renting on employment in 2001 disappears. The positive effect of living in an area with $20-40 \%$ social renting remains, although the effect is still hardly significant. The effect of deprivation shows that the higher the level of deprivation, the less likely it is that people are employed in 2001. The pattern observed in Table 3 is the same as in Table 2: the results show that on the CATT level tenure mix does have an effect on labour market outcomes, but the underlying mechanism is neighbourhood deprivation.

\section{--- Table 3 ---}

\section{Geographical scale of neighbourhoods}

All the models in Tables 2 and 3 included area characteristics on the CATT level. Previous work suggests that lower level geographies better represent neighbourhoods and there is evidence that neighbourhood effects are more pronounced when a lower geographical scale is used (see Buck, 2001; Bolster et al., 2007; Graham et al., 2009). To test the effect of a lower geographical scale, we reran Models 2 and 4 using neighbourhood characteristics on the Output Area level (see Table 4). As expected, the coefficients for the individual and household level characteristics remain similar to those identified with the CATT neighbourhood level models. There are however some remarkable differences between CATT and Output Area level for the effects of the area characteristics.

Model 2 (with a research population of unemployed SLS members in 1991) in Table 2 showed that there was no effect of the level of social renting on the CATT level after controlling for the level of deprivation on the CATT level. Model 5 is the same model, but now with Output Area level variables. The results show that after controlling for deprivation in the Output Area, living in a mixed tenure area (20-40\%, $40-60 \%$ and especially $60-80 \%$ social renting) has a positive effect on the probability to be employed in 2001 for those who were unemployed in 1991. This finding could indicate that mixing tenures on a low geographical scale (Output Areas with on average 199 people in Scotland) could benefit the unemployed in getting work. In addition, in Model 5 the effect of Output Area level deprivation on the probability to be employed in 2001 is much more pronounced than in Model 2 on the CATT level. This indicates that especially a high level of deprivation of direct neighbours and those in neighbouring streets has a strong negative impact on employment opportunities. Comparing Models 4 and 6 (with a research population of employed SLS members in 1991) shows no major differences between the effects of CATT level and Output Area level characteristics on the probability of employment in 2001.

\section{--- Table 4 ---}




\section{Conclusions}

The main aim of this paper was to further our understanding of the effect of neighbourhood tenure mix on individual employment outcomes using unique individual level longitudinal data for the whole of Scotland. Our results show a negative correlation between living in high concentrations of social housing (more than $80 \%$, measured at the CATT level) and transitions from unemployment to employment and the probability of staying in employment. We also found that the underlying mechanism for this is area level deprivation. At a much lower geographical scale, at the level of direct neighbours and neighbouring streets (Output Areas), we found two important effects. First, we found that after controlling for area deprivation, there was a significant positive correlation between living in areas with $40-80 \%$ social housing (mixed tenure areas) and the transition from unemployment to employment. This could support the idea of the importance of positive role models. Second, we found that the negative effects of area deprivation are stronger on a low geographical scale than when measured on a larger geographical scale. So it seems to matter more when your direct neighbours and those in neighbouring streets are deprived than when you live nearby concentrations of poverty.

As we pointed out in the literature review, also our work is by no means free from the problems commonly found in the neighbourhood effects literature as identified by Durlauf (2004). It is therefore the question whether the results found can be interpreted as real 'neighbourhood effects' or whether the outcomes of our models are the result of reversed causation due to omitted variable bias and selection effects. It is very likely that those most likely to be unemployed select 'themselves' into deprived neighbourhoods. If this is the case, it can not be concluded that deprived neighbourhood affect employment chances. More work is needed on the direction of causality in our models before strong conclusions can be drawn. The question remains what we can learn from our results with regard to the potential effectiveness of mixed tenure policies.

We found no clear evidence that it is beneficial to create pockets of owner occupation in predominantly socially rented neighbourhoods. Even if we believed that mixed neighbourhoods would have the desired effects, we think that it will be very difficult to create sustainable mixed tenure areas. There is evidence from the Netherlands that people do not want to live in mixed areas, including mixed tenure areas (Van Ham \& Feijten, 2008; see also Van Ham and Clark, forthcoming). Also, there is evidence that there is little interaction between tenure groups in mixed tenure neighbourhoods (Atkinson \& Kintrea, 1998; Jupp, 1999). In our analyses we found that individual level characteristics provide more explanation of employment outcomes than area level characteristics. Given the importance of individual characteristics and neighbourhood level deprivation in understanding employment transitions, tackling area deprivation, especially small concentrations of extreme poverty, should get priority. Not by replacing social renters by homeowners, but by investing in the lives of individuals. This is in line with what Cheshire notes: "forcing neighbourhoods to be mixed in social and economic terms is, therefore, mainly treating the symptoms of inequalities rather than the causes" (2008, p.30). Thus, greater efficacy will be gained through the use of individual level targeted policies aimed at improving individual experiences and opportunities, and tackling the causes of deprivation. 


\section{Acknowledgements}

The help provided by staff of the Longitudinal Studies Centre - Scotland (LSCS) is acknowledged. The LSCS is supported by the ESRC/JISC, the Scottish Funding Council, the Chief Scientist's Office and the Scottish Executive. The authors alone are responsible for the interpretation of the data. Census output is Crown copyright and is reproduced with the permission of the Controller of HMSO and the Queen's Printer for Scotland.

\section{References}

Allison, P. (2005) Fixed effects regression methods for longitudinal data using SAS. Cary, NC, SAS Institute Inc.

Arthurson, K. (2005), Social Mix and the Cities, Urban Policy and Research, 23: 519523.

Atkinson, R., Kintrea, K. (1998), Reconnecting Excluded Communities: The Neighbourhood Impacts of Owner Occupation, Edinburgh: Scottish Homes.

Atkinson, R., Kintrea K. (2000), Owner-occupation, social mix and neighbourhood impacts, Policy and Politics, 28: 93-108.

Atkinson, R., Kintrea K. (2002), Area Effects: What do they mean for British Housing and Regeneration Policy? European Journal of Housing Policy, 2: 147-166.

Bolster, A., Burgess, S., Johnston, R., Jones, K., Propper, C., Sarker, R. (2007), Neighbourhoods, households and income dynamics: a semi-parametric investigation of neighbourhood effects, Journal of Economic Geography, 7: 138.

Blume, L., Durlauf, S. (2001), The interactions-based approach to socioeconomic behaviour, In S. Durlauf, H. P. Young (eds), Social Dynamics. Cambridge: MIT Press.

Boyle, P., Cooke, T., Halfacree, K., and Smith, D. (2001), A cross-national comparison the impact of family migration on women's employment status, Demography, 38: 201-213.

Boyle, P. J., Feijten, P., Feng, Z., Hattersley, L., Huang, Z., Nolan, J. and Raab, G. (forthcoming) Cohort Profile: The Scottish Longitudinal Study (SLS). International Journal of Epidemiology.

Brock, W., Durlauf, S. (2001), Interactions-Based Models, In. J. Heckman, E. Leamer, (eds), Handbook of Econometrics Vol. 5. Elsevier Science B.V: 3297-3380.

Brock, W., Durlauf, S. (2003), Multinomial choice with social interactions, SSRI Working Paper No. 2003-1, University of Wisconsin.

Buck, N. (2001), Identifying Neighbourhood Effects on Social Exclusion, Urban Studies, 38: 2251-2275.

Carstairs, V., Morris, R. (1990), Deprivation and Health in Scotland. Health Bulletin., 48: $162-75$.

Cheshire (2008), Policies for Mixed Communities: Faith based Displacement Activity? Paper given at ESRC workshop on Gentrification and Social Mix, Kings College, London. $22^{\text {nd }}$ to $23^{\text {rd }}$ May 2008.

Cohen, J. and Cohen, P. (1975), Applied Multiple Regression/Correlation Analysis for the Behavioural Science, New York: John Wiley \& Sons.

Communities Scotland (2004), Future options for mixed tenure and registered social landlord (RSL) property in Edinburgh's pre-1919 tenements, PRECiS No. 36.

Dietz, R. D. (2002), The estimation of neighborhood effects in the social sciences: an 
interdisciplinary approach, Social Science Research, 31: 539-575.

Durlauf, S. (2004), Neighborhood effects. In J. V. Henderson and J.-F. Thisse (eds), Handbook of Regional and Urban Economics, Vol. 4 Cities and Geography, Amsterdam: Elsevier Science B. V: 2174-2242.

EU (1998), The 1998 Employment Guidelines, Council Resolution of 15, December 1997.

Galster, G. (2001), On the Nature of Neighbourhood, Urban Studies, 38: 2111-2124.

Galster, G. (2007), Neighbourhood Social Mix as a Goal of Housing Policy: A Theoretical Analysis, European Journal of Housing Policy, 7: 19-43.

Galster, G., Andersson, R., Musterd, S., Kauppinen, T,M. (2008),. Does neighborhood income mix affect earnings of adults? New evidence from Sweden, Journal of Urban Economics, 63: 858-870.

Gobillon, L., Selod, H., Zenou, Y., (2007), The Mechanisms of Spatial Mismatch, Urban Studies, 44: 2401-2427.

Goering, J., Feins, J.D., Richardson, T. M. (2002), A Cross-Site Analysis of Initial Moving to Opportunity Demonstration Results, Journal of Housing Research, 13: 1-30.

Graham, E., Manley, D., Hiscock, R., Boyle, P., Doherty, J. (2009), Mixing Housing Tenures: Is it Good for Social Well-being? Urban Studies, 46: 139-165.

Hochschild, J. (1991), The Politics of the Estranged Poor, Ethics 101, 3: 560-578.

Jones, C., Murie, A. (2006), The Right to Buy: Analysis and Evaluation of a Housing Policy, Oxford: WileyBlackwell Publishing.

Jupp, B. (1999), Living together: Community life on mixed tenure estates, London: DEMOS.

Kain, J. (1968), Housing Segregation, Negro Employment, and Metropolitan Decentralization, Quarterly Journal of Economics, 82: 175-197.

Katz, L., Kling, J., Liebman, J. (2001), Moving to Opportunity in Boston: Early Results of a Randomized Mobility Experiment, Quarterly Journal of Economics, 116: 607-654.

Kearns, A., Parkinson, M. (2001), The Significance of Neighbourhood, Urban Studies, 38: 2103-2110.

Kearns, A. (2002), Response: From Residential Disadvantage to Opportunity? Reflections on British and European Policy Research, Housing Studies, 17: 145150.

Kleinman, M. (2000), Include Me Out? The New Politics of Place and Poverty, Policy Studies, 21: 49-61.

Kling, J., Liebman, J., Katz, L., Sanbonmatsu, L. (2004), Moving to opportunity and tranquility: neighborhood effects on adult economic self-sufficiency and health from a randomized housing voucher experiment, Princeton IRS Working Paper 481.

Lee, B.A., Oropesa, R.S., Kanan, J.W. (1994), Neighborhood context and residentialmobility, Demography, 31: 249-270.

Ludwig, J., Duncan, G. J., Hirschfield, P. (2001), Urban poverty and juvenile crime: evidence from a randomized housing-mobility experiment, Quarterly Journal of Economics, 116: 655-680.

Manley, D., Flowerdew, R., Steel, D. (2006), Scales, levels and processes: Studying spatial patterns of British census variables, Computers, Environment and Urban Systems, 30: 143-160.

Manski, C. (1993), Identification of endogenous social effects: the reflection problem, Review of Economic Studies, 60: 531-542. 
Manski, C. (2000), Economics analysis of social interactions, Journal of Economic Perspectives, 14: 115-136.

Martin, G., Watkinson, J. (2003), Rebalancing communities: Introducing mixed incomes into existing rented housing estates, York: Joseph Rowntree Foundation.

McCulloch, A. (2001), Ward-level deprivation and individual social and economic outcomes in the British Household Panel Study, Environment and Planning A, 33: 667-684.

Moffitt, R. (2001), Policy interventions, low-level equilibria, and social interactions. In S. Durlauf and H. P. Young (eds), Social Dynamics. Cambridge: MIT Press.

Musterd, S. (2002), Response: Mixed housing policy: A European (Dutch), perspective, Housing Studies, 17: 139-143.

Musterd, S., Andersson R. (2005), Housing mix, social mix and social opportunities, Urban Affairs Review, 40: 761-790.

OECD, (1997), Meeting of the employment, labour and social affairs committee at ministerial level, Paris.

Ostendorf, W., Musterd, S., De Vos, S. (2001), Social Mix and the Neighbourhood Effect. Policy Ambitions and Empirical Evidence, Housing Studies, 16: 371380.

Pawson, H., Kirk, K., McIntosh, S. (2000), Assessing the impact of tenure diversification: the case of Niddrie, Edinburgh Scottish Homes, Edinburgh.

Permentier, M., Van Ham, M., Bolt G. (2007), Behavioural responses to neighbourhood reputations, Journal of Housing and the Built Environment, 22: 199-213.

Power, A. (1997), Estates on the Edge: the social consequences of mass housing in Europe, Houndsmills: Macmillan.

Preston, V., McLafferty, S. (1999), Spatial mismatch research in the 1990s: progress and potential, Papers in Regional Science, 78: 387-402.

Priemus, H. (1998), Redifferentiation of the Urban Housing Stock in the Netherlands: A Strategy to Prevent Spatial Segregation? Housing Studies, 13: 301-310.

Rosebaum, J. (1995), Changing the geography of opportunity by expanding residential choice: lessons from the gatreaux program, Housing Policy Debate, 6: 231-269.

Sampson, R., Morenoff, J., and Gannon-Rowley, T., (2002), Assessing 'neighbourhood effects': Social processes and new directions in research, Annual Review of Sociology, 28: 443-478.

Schwartz, A., Tajbakhsh, K. (1997), Mixed income housing: unanswered questions, Cityscape, 3: 71-92.

Schömann, K., O’Connell, P. (2002), Training and Employment Dynamics: Transitional Labour Markets in the European Union, Northampton: Edward Elgar Publishing.

Scottish Executive (2004), Scottish Executive Urban Rural Classification 2003-2004. Edinburgh: (www.scotland.gov.uk).

Scottish Government (2006), People and Place: Regeneration Policy Statement Edinburgh: (www.scotland.gov.uk).

Scottish Government, (2007), Discussion paper on the future direction of housing policy in Scotland. Edinburgh (www.scotland.gov.uk).

Scottish Homes (2001), Tenure Mix and Neighbourhood Regeneration. PRECiS No. 127.

Smith, G. R. (1999), Area-based Initiatives: The rationale and options for area 
targeting CASE paper 25, LSE.

Smith, G., Noble, M., Wright, G. (2001), Do we care about area effects? Environment and Planning A, 33: 1341-1344.

Tunstall, R. (2003), 'Mixed Tenure' policy in the UK: privitisation, pluralism or euphemism? Housing, Theory and Society, 20: 153-159.

Tunstall, R., Fenton, A. (2006), In the mix: A review of research on mixed income, mixed tenure and mixed communities, York: Housing Corporation, Joseph Rowntree Foundation, English Partnerships.

Van Ham M., Hooimeijer P. and Mulder C.H. (2001), Urban form and job access: Disparate realities in the Randstad, Journal of Economic and Social Geography, 92: 231-246.

Van Ham, M. (2002), Job access, workplace mobility, and occupational achievement. Delft: Eburon.

Van Ham, M. and Feijten P.M. (2008), Who wants to leave the neighbourhood? The effect of being different from the neighbourhood population on wishes to move, Environment and Planning A, 40: 1151-1170.

Van Ham, M., and Clark, W.A.V. (forthcoming), Neighbourhood mobility in context: household moves and changing neighbourhoods in the Netherlands, Environment and Planning A.

Wilson, W. J. (1987), The Truly disadvantaged, Chicago: University of Chicago Press.

Wilson, W. J. (1991), Another Look at The Truly Disadvantaged. Political Science Quarterly, 106: 639-656.

Wood, M. (2003), A Balancing Act? Tenure Diversification in Australia and the UK, Urban Policy and Research, 21: 45-56. 
Table 1: Variable summary statistics

\begin{tabular}{|c|c|c|}
\hline & Unemployed in 1991 & Employed in 1991 \\
\hline & $\mathrm{N}=3,639$ & $\mathrm{~N}=60,048$ \\
\hline Percentage employed in 2001 & $71.7 \%$ & $97.5 \%$ \\
\hline \multicolumn{3}{|l|}{ Individual and Household level variables } \\
\hline Age (average age in 1991) & 28.9 years & 32.9 years \\
\hline Female (reference = male) & $33.2 \%$ & $44.3 \%$ \\
\hline Ethnic (reference = non ethnic) & $0.9 \%$ & $0.7 \%$ \\
\hline Qualifications 2001 (reference = none) & $37.6 \%$ & $23.8 \%$ \\
\hline GCSE & $30.3 \%$ & $27.3 \%$ \\
\hline Highers & $13.3 \%$ & $16.3 \%$ \\
\hline $\mathrm{HNC} / \mathrm{D}$ & $7.5 \%$ & $8.5 \%$ \\
\hline Degree or higher & $11.3 \%$ & $24.1 \%$ \\
\hline Tenure 1991 (reference = owners) & $34.7 \%$ & $69.5 \%$ \\
\hline Social Renter & $58.1 \%$ & $24.3 \%$ \\
\hline Private Renter & $7.2 \%$ & $6.2 \%$ \\
\hline Partner Works 1991 (reference = not work) & $55.9 \%$ & $77.1 \%$ \\
\hline Change in health (reference = no LLTI) & $88.5 \%$ & $92.6 \%$ \\
\hline LLTI $91 \& 01$ & $1.1 \%$ & $0.8 \%$ \\
\hline LLTI 91 & $2.1 \%$ & $0.9 \%$ \\
\hline LLTI 01 & $8.3 \%$ & $5.7 \%$ \\
\hline Change in Household Type (reference = couple) & $55.4 \%$ & $73.9 \%$ \\
\hline 91 \& 01 Single & $9.4 \%$ & $4.8 \%$ \\
\hline 91 Single / 01 Couple & $4.4 \%$ & $3.7 \%$ \\
\hline 91 Couple / 01 Single & $30.8 \%$ & $17.6 \%$ \\
\hline Change in presence of children (reference $=$ Children) & $24.4 \%$ & $25.6 \%$ \\
\hline 91 / 01 No Children & $41.1 \%$ & $33.1 \%$ \\
\hline 91 No Child / 01 Child & $14.9 \%$ & $16.7 \%$ \\
\hline 91 Child / 01 No Child & $19.6 \%$ & $24.6 \%$ \\
\hline Moved (reference $=$ not moved) & $69.5 \%$ & $62.1 \%$ \\
\hline \multicolumn{3}{|l|}{ Neighbourhood level variables } \\
\hline Urban-rural classification 1991 (reference = remote) & $4.4 \%$ & $5.2 \%$ \\
\hline Accessible Rural Areas & $10.2 \%$ & $13.5 \%$ \\
\hline Remote Towns & $1.9 \%$ & $2.7 \%$ \\
\hline Small Towns & $10.0 \%$ & $10.7 \%$ \\
\hline Urban Areas & $31.2 \%$ & $31.2 \%$ \\
\hline Cities & $42.3 \%$ & $36.7 \%$ \\
\hline Social Renting 1991 (reference = 0 - 20\%) & $20.3 \%$ & $38.1 \%$ \\
\hline $20-40 \%$ & $17.1 \%$ & $23.0 \%$ \\
\hline $40-60 \%$ & $17.2 \%$ & $16.2 \%$ \\
\hline $60-80 \%$ & $22.9 \%$ & $14.4 \%$ \\
\hline $80-100 \%$ & $22.5 \%$ & $8.3 \%$ \\
\hline Carstairs Deprivation 1991 (Reference $=1$ (Least)) & $9.3 \%$ & $23.6 \%$ \\
\hline 2 & $14.9 \%$ & $22.8 \%$ \\
\hline 3 & $17.7 \%$ & $21.1 \%$ \\
\hline 4 & $24.5 \%$ & $19.1 \%$ \\
\hline 5 & $33.6 \%$ & $13.4 \%$ \\
\hline
\end{tabular}


Table 2: CATT level logistic regression of the probability of employment in 2001 for those unemployed in $1991(\mathrm{~N}=3,639)$

\begin{tabular}{|c|c|c|c|c|c|c|}
\hline \multirow{3}{*}{ Individual and Household level variables } & \multicolumn{3}{|c|}{ Model 1} & \multicolumn{3}{|c|}{ Model 2} \\
\hline & \multirow[t]{2}{*}{ Coef. } & \multicolumn{2}{|l|}{ S.e. ${ }^{1}$} & \multirow[t]{2}{*}{ Coef. } & \multicolumn{2}{|l|}{ S.e. $^{1}$} \\
\hline & & & & & & \\
\hline Age in years (1991) & -0.003 & 0.006 & & -0.004 & 0.005 & \\
\hline Female (reference = male) & 0.828 & 0.200 & $* * *$ & 0.837 & 0.200 & $* * *$ \\
\hline Ethnic (reference = non ethnic) & -0.284 & 0.482 & & -0.191 & 0.481 & \\
\hline \multicolumn{7}{|l|}{ Qualifications 2001 (reference $=$ none) } \\
\hline GCSE & 0.539 & 0.109 & $* * *$ & 0.530 & 0.108 & $* * *$ \\
\hline Highers & 0.625 & 0.146 & $* * *$ & 0.613 & 0.146 & $* * *$ \\
\hline $\mathrm{HNC} / \mathrm{D}$ & 1.173 & 0.221 & $* * *$ & 1.157 & 0.221 & $* * *$ \\
\hline Degree or higher & 1.027 & 0.181 & $* * *$ & 1.011 & 0.181 & $* * *$ \\
\hline \multicolumn{7}{|l|}{ Tenure 1991 (reference = owners) } \\
\hline Social Renter & -0.531 & 0.126 & $* * *$ & -0.534 & 0.126 & $* * *$ \\
\hline Private Renter & -0.733 & 0.177 & $* * *$ & -0.675 & 0.181 & $* * *$ \\
\hline Partner Works 1991 (reference = not work) & 0.409 & 0.145 & $* * *$ & 0.395 & 0.145 & $* * *$ \\
\hline \multicolumn{7}{|l|}{ Change in health (reference $=$ no LLTI) } \\
\hline LLTI $91 \& 01$ & -0.475 & 0.388 & & -0.495 & 0.388 & \\
\hline LLTI 91 & 0.029 & 0.292 & & 0.035 & 0.292 & \\
\hline LLTI 01 & -0.922 & 0.141 & $* * *$ & -0.913 & 0.141 & $* * *$ \\
\hline \multicolumn{7}{|l|}{ Change in Household Type (reference = couple) } \\
\hline 91 \& 01 Single & -1.061 & 0.147 & $* * *$ & -1.045 & 0.147 & $* * *$ \\
\hline 91 Single / 01 Couple & 0.411 & 0.267 & & 0.404 & 0.266 & \\
\hline 91 Couple / 01 Single & -0.674 & 0.103 & $* * *$ & -0.675 & 0.103 & $* * *$ \\
\hline \multicolumn{7}{|c|}{ Change in presence of children (reference = children) } \\
\hline 91 / 01 No Children & -0.530 & 0.130 & $* * *$ & -0.528 & 0.130 & $* * *$ \\
\hline 91 No Child / 01 Child & -0.028 & 0.167 & & -0.032 & 0.166 & \\
\hline 91 Child / 01 No Child & -0.117 & 0.145 & & -0.121 & 0.145 & \\
\hline Moved (reference = not moved) & 0.057 & 0.111 & & 0.060 & 0.112 & \\
\hline Female*Moved & -0.165 & 0.233 & & -0.180 & 0.234 & \\
\hline \multicolumn{7}{|l|}{ Neighbourhood level variables } \\
\hline \multicolumn{7}{|c|}{ Urban-rural classification 1991 (reference = remote) } \\
\hline Accessible Rural Areas & 0.484 & 0.250 & $*$ & 0.384 & 0.256 & \\
\hline Remote Towns & 0.495 & 0.389 & & 0.444 & 0.386 & \\
\hline Small Towns & 0.303 & 0.244 & & 0.237 & 0.245 & \\
\hline Urban Areas & 0.189 & 0.218 & & 0.141 & 0.219 & \\
\hline Cities & 0.172 & 0.213 & & 0.186 & 0.215 & \\
\hline \multicolumn{7}{|l|}{ Social Renting 1991 (reference $=0$ - 20\%) } \\
\hline $20-40 \%$ & -0.207 & 0.159 & & -0.131 & 0.177 & \\
\hline $40-60 \%$ & -0.138 & 0.178 & & 0.071 & 0.213 & \\
\hline $60-80 \%$ & -0.161 & 0.170 & & 0.160 & 0.216 & \\
\hline $80-100 \%$ & -0.431 & 0.175 & $* * *$ & -0.053 & 0.230 & \\
\hline \multicolumn{7}{|c|}{ Carstairs Deprivation 1991 (Reference $=1$ (Least)) } \\
\hline 2 & & & & -0.077 & 0.234 & \\
\hline 3 & & & & -0.174 & 0.246 & \\
\hline 4 & & & & -0.416 & 0.249 & $*$ \\
\hline 5 & & & & -0.529 & 0.263 & $* *$ \\
\hline Constant & 1.615 & 0.334 & $* * *$ & 1.787 & 0.371 & $* * *$ \\
\hline Wald chi2 & 439, $\mathrm{df}=29$, & & & $439, \mathrm{df}=33$ & $\operatorname{sig}=0.000$ & \\
\hline Initial Log pseudo-likelihood & -1889 & & & -1889 & & \\
\hline Log pseudo-likelihood & -1634 & & & -1630 & & \\
\hline
\end{tabular}


Table 3: CATT level logistic regression of the probability of employment in 2001 for those employed in $1991(\mathrm{~N}=60,048)$

\begin{tabular}{|c|c|c|c|c|c|c|}
\hline \multirow{3}{*}{ Individual and Household level variables } & \multicolumn{3}{|c|}{ Model 3} & \multicolumn{3}{|c|}{ Model 4} \\
\hline & Coef. & \multicolumn{2}{|l|}{ S.e. ${ }^{1}$} & Coef. & \multicolumn{2}{|l|}{ S.e. ${ }^{1}$} \\
\hline & & & & & & \\
\hline Age in years (1991) & 0.006 & 0.003 & $*$ & 0.005 & 0.003 & \\
\hline Female (reference $=$ male) & 0.873 & 0.088 & $* * *$ & 0.872 & 0.088 & $* * *$ \\
\hline Ethnic (reference = non ethnic) & -0.552 & 0.247 & $* *$ & -0.533 & 0.247 & $* *$ \\
\hline \multicolumn{7}{|l|}{ Qualifications 2001 (reference $=$ none) } \\
\hline GCSE & 0.269 & 0.067 & $* * *$ & 0.261 & 0.067 & $* * *$ \\
\hline Highers & 0.454 & 0.082 & $* * *$ & 0.444 & 0.082 & $* * *$ \\
\hline $\mathrm{HNC} / \mathrm{D}$ & 0.391 & 0.101 & $* * *$ & 0.388 & 0.102 & $* * *$ \\
\hline Degree or higher & 0.681 & 0.085 & $* * *$ & 0.667 & 0.085 & $* * *$ \\
\hline \multicolumn{7}{|l|}{ Tenure 1991 (reference = owners) } \\
\hline Social Renter & -0.513 & 0.064 & $* * *$ & -0.510 & 0.064 & $* * *$ \\
\hline Private Renter & -0.300 & 0.101 & $* * *$ & -0.282 & 0.101 & $* * *$ \\
\hline Partner Works 1991 (reference = not work) & 0.341 & 0.073 & $* * *$ & 0.335 & 0.074 & $* * *$ \\
\hline \multicolumn{7}{|l|}{ Change in health (reference = no LLTI) } \\
\hline LLTI 91 \& 01 & -1.069 & 0.173 & $* * *$ & -1.068 & 0.173 & $* * *$ \\
\hline LLTI 91 & 0.324 & 0.279 & & 0.325 & 0.279 & \\
\hline LLTI 01 & -0.990 & 0.074 & $* * *$ & -0.989 & 0.074 & $* * *$ \\
\hline Change in Household Type (reference $=$ cou & & & & & & \\
\hline 91 \& 01 Single & -0.824 & 0.093 & $* * *$ & -0.804 & 0.094 & $* * *$ \\
\hline 91 Single / 01 Couple & 0.133 & 0.161 & & 0.149 & 0.161 & \\
\hline 91 Couple / 01 Single & -0.837 & 0.058 & $* * *$ & -0.831 & 0.058 & $* * *$ \\
\hline Change in presence of children (reference $=$ & & & & & & \\
\hline 91 / 01 No Children & -0.223 & 0.068 & $* * *$ & -0.219 & 0.068 & $* * *$ \\
\hline 91 No Child / 01 Child & 0.024 & 0.092 & & 0.029 & 0.092 & \\
\hline 91 Child / 01 No Child & -0.216 & 0.072 & $* * *$ & -0.221 & 0.072 & $* * *$ \\
\hline Moved (reference = not moved) & 0.177 & 0.064 & $* * *$ & 0.171 & 0.064 & $* * *$ \\
\hline Female*Moved & -0.490 & 0.108 & $* * *$ & -0.487 & 0.108 & $* * *$ \\
\hline Neighbourhood level variables & & & & & & \\
\hline Urban-rural classification 1991 (reference = & & & & & & \\
\hline Accessible Rural Areas & 0.036 & 0.124 & & 0.001 & 0.173 & \\
\hline Remote Towns & 0.019 & 0.173 & & 0.060 & 0.134 & \\
\hline Small Towns & 0.078 & 0.133 & & 0.032 & 0.117 & \\
\hline Urban Areas & 0.029 & 0.117 & & 0.013 & 0.124 & \\
\hline Cities & 0.061 & 0.116 & & 0.114 & 0.116 & \\
\hline Social Renting 1991 (reference = 0 - 20\%) & & & & & & \\
\hline $20-40 \%$ & 0.127 & 0.075 & $*$ & 0.161 & 0.084 & $*$ \\
\hline $40-60 \%$ & 0.038 & 0.077 & & 0.149 & 0.094 & \\
\hline $60-80 \%$ & -0.125 & 0.082 & $*$ & 0.089 & 0.104 & \\
\hline $80-100 \%$ & -0.174 & 0.095 & $* * *$ & 0.167 & 0.124 & \\
\hline Carstairs Deprivation 1991 (Reference $=1 \mathrm{c}$ & & & & & & \\
\hline 2 & & & & 0.013 & 0.091 & \\
\hline 3 & & & & -0.071 & 0.096 & \\
\hline 4 & & & & -0.176 & 0.105 & $*$ \\
\hline 5 & & & & -0.440 & 0.117 & $* * *$ \\
\hline Constant & 3.018 & 0.194 & $* * *$ & 3.051 & 0.201 & $* * *$ \\
\hline Wald chi2 & 1073, df= & , sig $=0.0$ & & $1104, \mathrm{df}=33$ & $=0.000$ & \\
\hline Initial Log pseudo-likelihood & -8185 & & & 8185 & & \\
\hline Log pseudo-likelihood & -7638 & & & -7623 & & \\
\hline
\end{tabular}


$\underline{\text { Table 4: Output Area level logistic regression for models } 2 \text { and } 4(\mathrm{~N}=3,639 ; \mathrm{N}=60,048)}$

Model 5

Unemployed 1991

Coef. $\quad$ S.e. $^{1}$

\section{Individual and Household level variables}

\begin{tabular}{|c|c|c|c|c|c|c|}
\hline Age in years (1991) & -0.004 & 0.006 & & 0.005 & 0.003 & \\
\hline Female (reference = male) & 0.845 & 0.200 & $* * *$ & 0.879 & 0.089 & $* * *$ \\
\hline Ethnic (reference = non ethnic) & -0.093 & 0.471 & & -0.551 & 0.250 & $* *$ \\
\hline \multicolumn{7}{|l|}{ Qualifications 2001 (reference = none) } \\
\hline GCSE & 0.515 & 0.109 & $* * *$ & 0.254 & 0.067 & $* * *$ \\
\hline Highers & 0.590 & 0.147 & $* * *$ & 0.429 & 0.082 & $* * *$ \\
\hline $\mathrm{HNC} / \mathrm{D}$ & 1.164 & 0.222 & $* * *$ & 0.359 & 0.102 & $* * *$ \\
\hline Degree or higher & 0.984 & 0.185 & $* * *$ & 0.636 & 0.083 & $* * *$ \\
\hline \multicolumn{7}{|l|}{ Tenure 1991 (reference = owners) } \\
\hline Social Renter & -0.536 & 0.148 & $* * *$ & -0.397 & 0.072 & $* * *$ \\
\hline Private Renter & -0.564 & 0.184 & $* * *$ & -0.288 & 0.102 & $* * *$ \\
\hline Partner Works 1991 (reference = not work) & 0.390 & 0.144 & $* * *$ & 0.331 & 0.074 & $* * *$ \\
\hline \multicolumn{7}{|l|}{ Change in health (reference $=$ no LLTI) } \\
\hline LLTI 91 \& 01 & -0.495 & 0.381 & & -1.061 & 0.172 & $* * *$ \\
\hline LLTI 91 & 0.010 & 0.293 & & 0.320 & 0.279 & \\
\hline LLTI 01 & -0.925 & 0.140 & $* * *$ & -0.986 & 0.072 & $* * *$ \\
\hline \multicolumn{7}{|l|}{ Change in Household Type (reference = couple) } \\
\hline 91 \& 01 Single & -1.007 & 0.150 & $* * *$ & -0.801 & 0.093 & $* * *$ \\
\hline 91 Single / 01 Couple & 0.404 & 0.266 & & 0.835 & 0.161 & \\
\hline 91 Couple / 01 Single & -0.674 & 0.103 & $* * *$ & -0.835 & 0.057 & $* * *$ \\
\hline \multicolumn{7}{|c|}{ Change in presence of children (reference $=$ Children) } \\
\hline 91 / 01 No Children & -0.541 & 0.132 & $* * *$ & -0.221 & 0.069 & $* * *$ \\
\hline 91 No Child / 01 Child & -0.042 & 0.170 & & 0.254 & 0.092 & \\
\hline 91 Child / 01 No Child & -0.129 & 0.145 & & -0.215 & 0.073 & $* * *$ \\
\hline Moved (reference = not moved) & 0.086 & 0.112 & & 0.181 & 0.064 & $* * *$ \\
\hline Female*Moved & -0.200 & 0.233 & & -0.487 & 0.107 & $* * *$ \\
\hline \multicolumn{7}{|l|}{ Neighbourhood level variables } \\
\hline \multicolumn{7}{|c|}{ Urban-rural classification 1991 (reference = remote) } \\
\hline Accessible Rural Areas & 0.108 & 0.222 & & 0.030 & 0.127 & \\
\hline Remote Towns & 0.356 & 0.256 & & 0.054 & 0.175 & \\
\hline Small Towns & 0.469 & 0.379 & & 0.095 & 0.136 & \\
\hline Urban Areas & 0.234 & 0.251 & & 0.051 & 0.119 & \\
\hline Cities & 0.226 & 0.219 & & 0.105 & 0.119 & \\
\hline \multicolumn{7}{|l|}{ Social Renting 1991 (reference = 0 - 20\%) } \\
\hline $20-40 \%$ & 0.379 & 0.221 & $*$ & 0.131 & 0.098 & \\
\hline $40-60 \%$ & 0.436 & 0.200 & $* *$ & -0.074 & 0.092 & \\
\hline $60-80 \%$ & 0.625 & 0.194 & $* * *$ & -0.014 & 0.097 & \\
\hline $80-100 \%$ & 0.259 & 0.200 & & -0.144 & 0.107 & \\
\hline \multicolumn{7}{|c|}{ Carstairs Deprivation 1991 (Reference = 1 (Least)) } \\
\hline 2 & -0.136 & 0.257 & & 0.055 & 0.085 & \\
\hline 3 & -0.549 & 0.254 & $* *$ & -0.173 & 0.088 & $*$ \\
\hline 4 & -0.893 & 0.256 & $* * *$ & -0.139 & 0.096 & \\
\hline 5 & -0.944 & 0.263 & $* * *$ & -0.358 & 0.108 & $* * *$ \\
\hline Constant & 1.858 & 0.380 & $* * *$ & 3.136 & 0.203 & $* * *$ \\
\hline Wald chi2 & \multicolumn{3}{|c|}{$440, \mathrm{df}=29, \mathrm{sig}=0.000$} & \multicolumn{3}{|c|}{$1131, \mathrm{df}=33, \mathrm{sig}=0.000$} \\
\hline Initial Log pseudo-likelihood & \multicolumn{3}{|l|}{1889} & \multicolumn{3}{|l|}{8185} \\
\hline Log pseudo-likelihood & \multicolumn{3}{|l|}{1618} & \multicolumn{3}{|l|}{7625} \\
\hline
\end{tabular}

